\title{
Regulation of Natural Cell Death in Dopaminergic Neurons of the Substantia Nigra by Striatal Glial Cell Line-Derived Neurotrophic Factor In Vivo
}

\author{
Tinmarla Frances 0o, ${ }^{1}$ Nikolai Kholodilov, ${ }^{1}$ and Robert E. Burke ${ }^{1,2}$ \\ Departments of ${ }^{1}$ Neurology and ${ }^{2}$ Pathology, The College of Physicians and Surgeons, Columbia University, New York, New York, 10032
}

\begin{abstract}
Dopamine (DA) neurons of the substantia nigra undergo a developmental cell death event that is biphasic, with peaks just after birth and at postnatal day 14. As envisioned by neurotrophic theory, this cell death is likely to be regulated by target interactions because it is augmented by their disruption. However, the nature of the trophic molecules mediating this regulation are unknown. We showed in vitro that glial cell line-derived neurotrophic factor (GDNF) is able to suppress apoptotic death in DA neurons in postnatal primary culture. We now demonstrate in vivo that administration of GDNF into the striatal target is able to suppress apoptosis. Consistent with a possible physiologic role for endogenous striatal GDNF in regulating this event, two anti-GDNF neutralizing antibodies augment cell death. These antibodies augment cell death only during the first (immediately postnatal) phase of the biphasic death event. We conclude that GDNF is the leading candidate for a target-derived neurotrophic factor for the regulation of the early phase of natural cell death in DA neurons.
\end{abstract}

Key words: apoptosis; programmed cell death; neurotrophic factors; Parkinson's disease; striatum; substantia nigra

\section{Introduction}

In developing neural systems, natural cell death eliminates $50 \%$ or more of neuronal populations (Cowan et al., 1984; Clarke, 1985; Oppenheim, 1991). There is now much evidence that target regulation of the natural cell death event is mediated by a limiting abundance of neurotrophic factors, for which projecting terminals compete (Clarke, 1985; Barde, 1989). It is important to recognize, however, that most of the evidence on which these concepts of classic neurotrophic theory rest derive from studies of neuronal systems that project to the periphery, and much less is known about mechanisms within the CNS.

One central neuronal population of particular interest is comprised of the dopamine (DA) neurons of the substantia nigra (SN) because this is the population that degenerates to the greatest extent in Parkinson's disease. Of great interest to the neurobiology of this disease are the neurotrophic factors that regulate the viability of these neurons during development and that ultimately determine their number in mature brain.

We showed that these neurons undergo natural cell death during development (Janec and Burke, 1993; Oo and Burke, 1997; Jackson-Lewis et al., 2000). In rodents, the event occurs primarily during the first 2 postnatal weeks. It is biphasic, with a first major peak just after birth and a second at postnatal day 14 (P14). We showed that this natural cell death is likely to be regulated by interactions with the target of these neurons, the striatum, because disruption of these interactions by striatal lesion (Macaya et al., 1994), DA terminal destruction (Marti et al.,

\footnotetext{
Received Dec. 18, 2002; revised March 21, 2003; accepted March 24, 2003.

This work was supported by National Institutes of Health Grants NS26836 and NS38370, The Parkinson's Disease Foundation, and the Lowenstein Foundation. We thank Amgen (Thousand 0aks, CA) for generously providing recombinant human GDNF for these studies.

Correspondence should be addressed to Robert E. Burke, Department of Neurology, Room 308, Black Building, Columbia University, 650 West 168th Street, New York, NY 10032. E-mail: rb43@columbia.edu.

Copyright $\odot 2003$ Society for Neuroscience $\quad$ 0270-6474/03/235141-08\$15.00/0
}

1997), or axotomy (El-Khodor and Burke, 2002) leads to an induction of death. There is also extensive evidence from in vitro studies supporting the concept that striatal targets support the viability of developing DA neurons (Prochiantz et al., 1979; Hemmendinger et al., 1981; Hoffmann et al., 1983; Tomozawa and Appel, 1986). However, the specific neurotrophic factors derived from striatum regulating the cell death event in DA neurons are unknown.

One candidate has been glial cell line-derived neurotrophic factor (GDNF), which was identified on the basis of its ability to support the development of embryonic mesencephalic DA neurons (Lin et al., 1993). In keeping with a possible role for GDNF, its mRNA is present in striatum and expressed at highest levels during early postnatal development (Schaar et al., 1993; Stromberg et al., 1993; Blum and Weickert, 1995; Choi-Lundberg and Bohn, 1995; Golden et al., 1999). GDNF protein has also been identified in striatum early in development (Lopez-Martin et al., 1999). We showed that, among nine neurotrophic factors reported to support DA mesencephalic neurons in embryonic culture, GDNF alone was able to support DA neurons by suppressing apoptosis in a postnatal culture model (Burke et al., 1998). Other members of the GDNF family of ligands have been discovered, including neurturin (Kotzbauer et al., 1996), persephin (Milbrandt et al., 1998), and artemin (Baloh et al., 1998); whether they have similar properties is unknown.

The strongest evidence to date against a role for GDNF as a physiologic trophic factor for developing SN DA neurons is that homozygous null mice for GDNF (Moore et al., 1996; Pichel et al., 1996; Sanchez et al., 1996) and for GDNF receptor $\alpha 1$ (GFR $\alpha 1$ ) (Cacalano et al., 1998; Enomoto et al., 1998) show no reduction in the number of SN DA neurons at birth. However, these mutations are perinatal lethal as a result of the absence of kidneys, so these mice die before most of the postnatal natural cell death event has occurred. To further pursue the possible role of 
GDNF as a physiologic striatal target-derived neurotrophic factor for SN DA neurons, we assessed the effects of striatal GDNF injection and passive immunization "knock down" on natural cell death.

\section{Materials and Methods}

Animal surgery: intrastriatal injections. Timed, multiple pregnancy Sprague Dawley female rats were obtained from Charles River Laboratories (Wilmington, MA) 1 week before delivery. The day of delivery was defined as P1 (Janec and Burke, 1993; Oo and Burke, 1997). If delivery occurred in the morning, rat pups were injected later that day (P1). If they were delivered in the afternoon, they were injected the next morning (P2). They were always injected within $24 \mathrm{hr}$ of birth.

For intrastriatal injection of GDNF and controls, pups were anesthetized by hypothermia and placed prone on a chilled ceramic plate. A midline scalp incision was made, and a hole was made in the skull $1.0 \mathrm{~mm}$ anterior and $2.5 \mathrm{~mm}$ left of the bregma. The needle of a $5.0 \mu \mathrm{l}$ Hamilton syringe, held in a stereotaxic frame, was inserted to a depth $2.5 \mathrm{~mm}$ ventral to dura. A solution of GDNF (for the pilot study, Intergen, Purchase, NY; for the full study, Amgen, Thousand Oaks, CA) at $1.0 \mu \mathrm{g}$ to 1.0 $\mu \mathrm{l}$ of PBS was infused over $1 \mathrm{~min}$. After the injection was complete, the needle was slowly withdrawn after an interval of $1 \mathrm{~min}$. Brain-derived neurotrophic factor (BDNF) (Intergen), cytochrome $c$ (Sigma, St. Louis, $\mathrm{MO}$ ) (both at $1 \mu \mathrm{g}$ to $1.0 \mu \mathrm{l}$ ), and vehicle (PBS) were injected as controls. After injection, pups were placed at $34^{\circ} \mathrm{C}$ in a Harvard small animal incubator until recovery.

For intrastriatal injection of anti-GDNF neutralizing antibodies, a 28 gauge cannula was inserted into the striatum as described. For an $80 \mu \mathrm{g}$ dose, anti-GDNF $(20 \mu \mathrm{g} / \mu \mathrm{l})$ or goat IgG control was infused by pump (Harvard Apparatus, Holliston, MA) at a rate of $0.25 \mu \mathrm{l} / \mathrm{min}$ over $8 \mathrm{~min}$ in two separate sessions, morning and afternoon. For 40, 20, and $10 \mu \mathrm{g}$, single afternoon doses were given by pump as $2.0 \mu \mathrm{l}$ over $8 \mathrm{~min}$. For 5.0 $\mu \mathrm{g}$, a single dose was given in $1.0 \mu \mathrm{l}$. For these studies, both AB-212-NA (affinity-purified IgG goat polyclonal) and MAB212 (affinity-purified IgG mouse monoclonal) were used (both from R \& D Systems, Minneapolis, MN). Both antibodies were raised against Escherichia coli-derived recombinant human GDNF. Both of these antibodies have been demonstrated to neutralize recombinant human GDNF in a chick dorsal root ganglion survival assay (R \& D Systems), and MAB212 has, in addition, been demonstrated to neutralize recombinant rat GDNF in a rat primary motor neuron culture (Arce et al., 1998). To determine whether either of these antibodies cross-react with other GDNF family ligands, Western blot analysis was performed using both recombinant human GDNF (Amgen) and rat GDNF [molecular weight (MW) of $15 \mathrm{kDa}$; R \& D Systems] compared with mouse neurturin (MW of $12 \mathrm{kDa}$; R \& D Systems), mouse artemin (MW of $12 \mathrm{kDa}$; R \& D Systems), and human persephin (MW of $21 \mathrm{kDa}$; Leinco Technologies, St. Louis, MO). Neither antibody cross-reacted with these other ligands (Fig. 1).

Intrastriatal injection procedures were approved by the Columbia University Institutional Animal Care and Use Committee.

Tissue preparation and immunohistochemistry. The day after striatal injection, rat pups were anesthetized with Halothane and perfused via an intracardiac cannula with $0.9 \% \mathrm{NaCl}$, followed by $4 \%$ paraformaldehyde in $0.1 \mathrm{M}$ phosphate buffer, $\mathrm{pH}$ 7.1. Each brain was carefully removed and postfixed in the same fixative for 1 week. The brain was then cryoprotected in $20 \%$ sucrose in fixative for $24-48 \mathrm{hr}$ and then rapidly frozen in isopentane on dry ice. The brain was cut at $20 \mu \mathrm{m}$ on a cryostat, and SN sections were processed free-floating for tyrosine hydroxylase (TH) immunoreactivity. For cell body staining, SN sections were incubated with a mouse monoclonal antibody at 1:40 (MAB5280; Chemicon, Temecula, CA) in PBS- $10 \%$ horse serum for $24 \mathrm{hr}$ at $4^{\circ} \mathrm{C}$ with agitation. After a wash in PBS, sections were incubated with biotinylated horse anti-mouse (Vector Laboratories, Burlingame, CA) at 1:50 in PBS-10\% horse serum for $24 \mathrm{hr}$ at $4^{\circ} \mathrm{C}$. For $\mathrm{TH}$ fiber staining, striatal sections were pretreated with PBS- $0.5 \%$ bovine serum albumin (BSA) $-0.1 \%$ Triton for $30 \mathrm{~min}$ at $4^{\circ} \mathrm{C}$. After washes in PBS, sections were incubated with anti-TH rabbit polyclonal antibody at 1:1000 (Calbiochem, La Jolla, CA) in PBS-BSA for $48 \mathrm{hr}$ at $4^{\circ} \mathrm{C}$. After washes in PBS-BSA, striatal sections were incubated

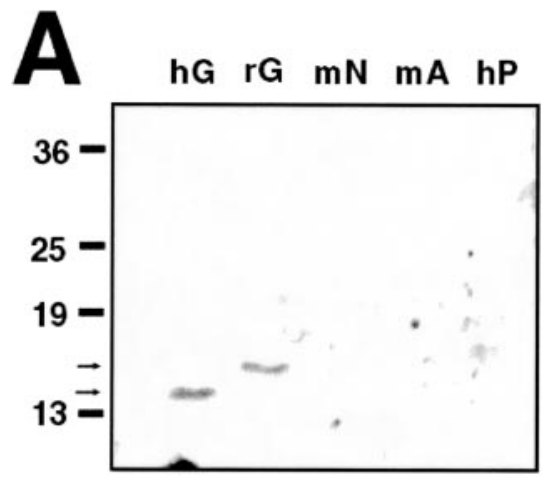

B

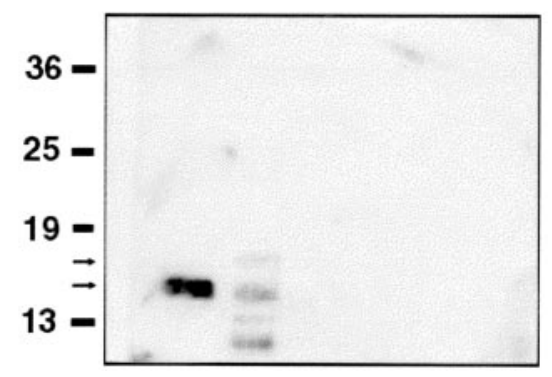

Figure 1. Anti-GDNF neutralizing antibodies do not cross-react with other GDNF family ligands. A, Recombinant human GDNF (hG), recombinant rat GDNF $(\mathrm{rG})$, mouse neurturin $(\mathrm{mN})$, mouse artemin $(\mathrm{mA})$, and human persephin (hP) were electrophoresed at $10 \mathrm{ng} / \mathrm{lane}$ and probed with the goat anti-GDNF polyclonal antibody at 1:400. Recombinant human and rat GDNF are detected at 15 and $16 \mathrm{kDa}$ (arrows). No cross-reactivity is detected for mouse neurturin $(12 \mathrm{kDa})$, mouse artemin $(12 \mathrm{kDa})$, or human persephin $(21 \mathrm{kDa})$. B, The recombinant proteins were electrophoresed at $100 \mathrm{ng} / \mathrm{lane}$ and probed with the mouse anti-GDNF monoclonal antibody at 1:100. The $15 \mathrm{kD}$ a form of recombinant human GDNF is again detected, as are 15, 16 , and lower MW forms of rat GDNF. There is no cross-reactivity with other GDNF family ligands.

with biotinylated Protein A at 1:100 for $1 \mathrm{hr}$ at room temperature. Sections for either cell body or fiber staining were then treated with avidinbiotinylated horseradish peroxidase complexes (ABC; Vector Laboratories), followed by incubation with diaminobenzidine as chromagen. Sections were mounted onto gelatin-coated slides, dehydrated, counterstained with thionin, and coverslipped. Striatal sections were taken from each brain for thionin staining, to confirm the injection site, and for $\mathrm{TH}$ immunoperoxidase staining of dopaminergic fibers.

Qualitative morphologic analysis of apoptosis in dopamine neurons. In the TH immunoperoxidase-stained sections, apoptosis was identified at the light microscope level by performing a thionin counterstain and visualizing intranuclear chromatin clumps at $600 \times$ as one or more intensely basophilic, homogeneously stained, round and distinctly bounded structures. We showed previously that, for natural cell death in dopamine neurons and for induction of this death event by either striatal lesion or the injection of 6-OHDA, apoptotic profiles so identified are confirmed to be apoptotic by electron microscopy (Macaya et al., 1994; Jackson-Lewis et al., 2000). Profiles so identified can also be confirmed as apoptotic by terminal deoxynucleotidyl transferase-mediated dUTP nick end labeling, suppressed silver staining, and immunostaining for activated caspase-3 and caspase cleavage products (Macaya et al., 1994; Marti et al., 1997; Jackson-Lewis et al., 2000).

Quantitative morphologic analysis. Apoptotic profiles in each SN were quantified by scanning the $\mathrm{SN}$ in its entirety on all available sections from each brain at $600 \times$. For the studies of GDNF suppression of natural cell death, an average of 17 sections per brain were analyzed. Apoptotic profiles were identified as cellular profiles containing one or more distinct, rounded basophilic chromatin clumps. We showed previously, using a physical disector technique (Gundersen, 1986), that apoptotic profiles, as defined, are rarely split by the microtome blade (Oo and Burke, 1997). 
Clarke and Oppenheim (1995) have demonstrated a similar result. Thus, apoptotic profiles, identified by focusing down through the section, represent unique and unbiased counts, and we used this method of quantification in our previous studies of natural cell death in dopamine neurons (Oo and Burke, 1997; Jackson-Lewis et al., 2000). To assess the number of apoptotic profiles derived from dopaminergic neurons of the substantia nigra pars compacta $(\mathrm{SNpc})$, we previously used two sets of criteria: cellular and regional. An apoptotic profile was considered to be dopaminergic by the cellular criterion if its cytoplasm was TH positive. In addition to counting profiles that are dopaminergic by this cellular criterion, we also counted profiles that are in the SNpc by a regional criterion. Our reason for using this regional criterion is that, as neurons die by apoptosis, it becomes no longer possible to identify their original phenotype by cytoplasmic markers. As they die, they are stripped of cytoplasm (Macaya et al., 1994), and there is diminished expression of these markers (Freeman et al., 1994). Indeed, we showed recently in a model of induced developmental death of neurons in the SNpc that, when it is possible to identify the phenotype of the dying cell, $91 \%$ are neurons, but it is possible to identify the phenotype only in $6 \%$ of instances (El-Khodor et al., 2002). Thus, if only counts of profiles with known phenotype are to be used, then the large majority of apoptotic profiles would not be accounted for. In the SNpc during development, $90 \%$ of the neurons are dopaminergic (Parish et al., 2001). Therefore, by ascertaining regional counts, we retain information about the large majority of dying neurons, nearly all of which are dopaminergic. The likely dopaminergic origin of these profiles is supported by our observations that there is an exact temporal correspondence between regional and cellular counts in the course of natural cell death, and there is a high correlation between counts obtained using the two criteria ( $r=0.939$ ) (Oo and Burke, 1997).

Quantitative analysis of apoptosis in the striatum. The first injected animals in each of the three conditions (cytochrome $c$, BDNF, and GDNF) in each of five consecutive litters were selected for the analysis of apoptosis in the striatum. Three thionin-stained striatal sections in the Paxinos-Watson (Paxinos and Watson, 1982) planes 8.7-10.2 were selected, as close to the injection site as possible without evidence of direct injury by the cannula. Comparable striatal planes were available for all animals. All sections were scanned in their entirety at $600 \times$, and the number of apoptotic profiles, as defined above, were counted. Results were expressed as the mean number of profiles per section.

Density of striatal dopaminergic fiber immunoperoxidase staining. In five representative animals in each of the injection groups, two TH immunoperoxidase-stained striatal sections in planes 9.2 or 9.7 were examined for the optical density of staining, as described previously

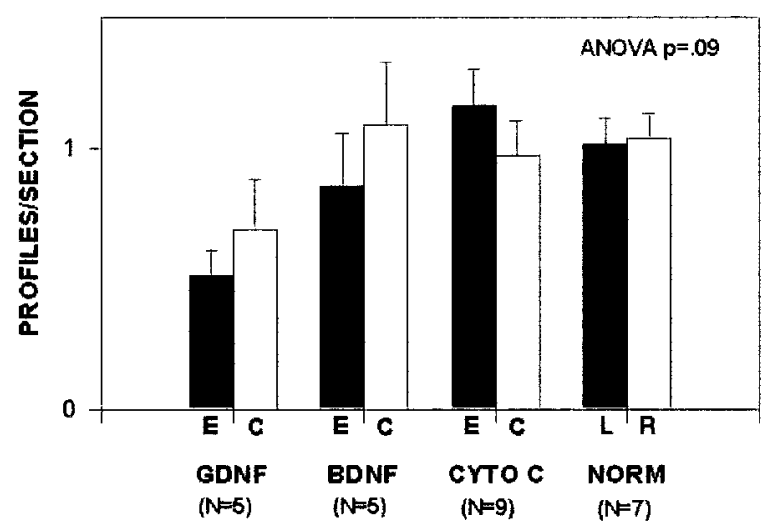

Figure 2. Preliminary data for a power analysis of the ability of GDNF to suppress natural cell death in DA neurons of the SN. P1 rats were injected with $1.0 \mu \mathrm{g} / 1.0 \mu \mathrm{l} \mathrm{GDNF}$ (Intergen) or controls and were killed the next day. The number of apoptotic profiles in $\mathrm{SN}$ was determined by the regional and cellular criteria defined in Materials and Methods. This preliminary analysis revealed an ability of GDNF to reduce cell death on the experimental (E; black bars) side of GDNF-injected animals compared with noninjected normal (NORM) animals by $\sim 50 \%$. The mean SD was 0.4 profiles per section across all groups. Note that there is no difference between the cytochrome c (CYTO C) and normal (NORM) controls (L, left; R, right). White bars represent the noninjected contralateral control $(C)$ side for each group.
(Burke et al., 1990), using an Imaging Research (St. Catharines, Ontario, Canada) Analytical Imaging Station.

\section{Results}

\section{Natural cell death in SN DA neurons is suppressed by} intrastriatal GDNF

Recognizing that the prevalence of apoptotic profiles is low during normal developmental cell death (Janec and Burke, 1993; Oo and Burke, 1997; Jackson-Lewis et al., 2000), we sought first to determine by pilot study the anticipated magnitude of the effect of $1.0 \mu \mathrm{g}$ of intrastriatal GDNF and its variability, for purposes of performing a power analysis. P1 rats were injected with commercially available GDNF (recombinant human GDNF; Intergen)

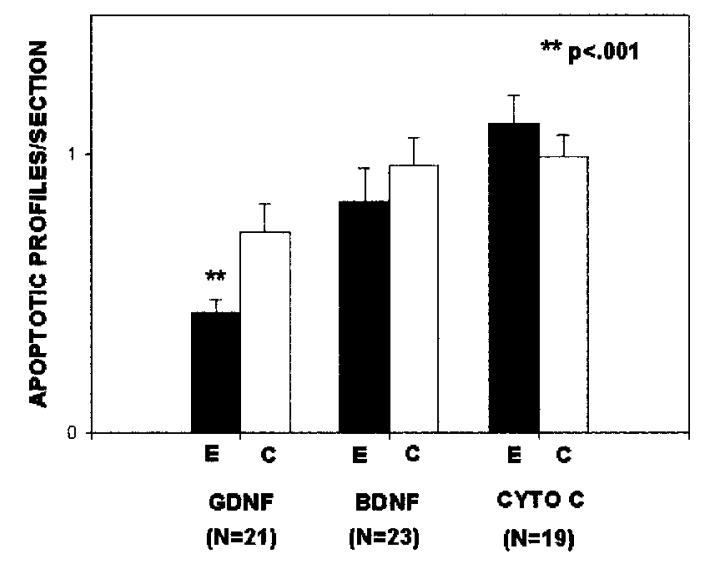

A

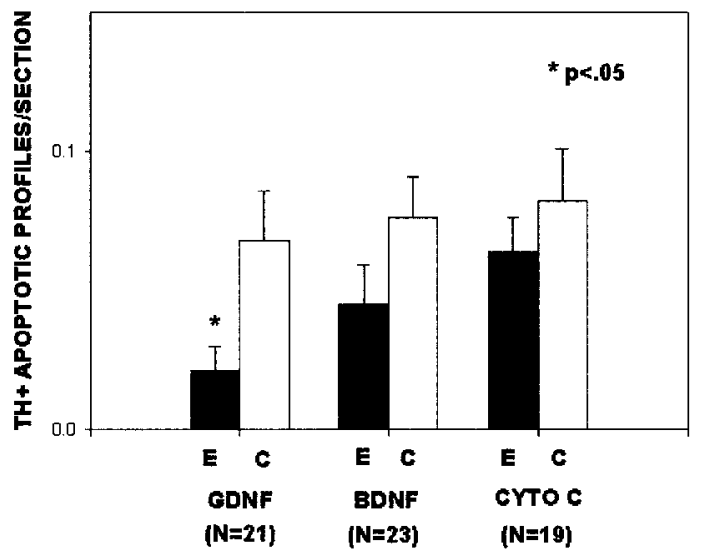

B

Figure 3. GDNF injected into the striatum reduces natural cell death among DA neurons of the SN. A, Rat pups were injected intrastriatally with $1.0 \mu \mathrm{g} / 1.0 \mu \mathrm{l}$ GDNF (Amgen), BDNF (Intergen), or cytochrome c (CYTO C) on P1 or P2 (but always within $24 \mathrm{hr}$ of birth) and were killed the next day. All apoptotic profiles within the SN meeting cellular or regional criteria for being dopaminergic were counted on all available sections from each brain and expressed as the mean number of apoptotic profiles per section. There is a significant ( $p<0.001$; ANOVA) decrease in the number of apoptotic profiles on the injected side (E, experimental) of the GDNF animals. There is a trend for an effect on the noninjected, contralateral ( $C$, control) side, but this did not reach significance. $B$, The sections analyzed in $A$ were also analyzed for only those profiles that met cellular criteria for being dopaminergic, i.e., these were apoptotic profiles with TH-positive cytoplasm. This analysis confirms the ability of GDNF to suppress natural cell death in DA neurons. 
and were killed the next day. Figure 2 shows that this injection led to an $\sim 50 \%$ suppression in the level of natural cell death, with a mean SD of 0.4 profiles per section. We determined that, to have a power of 0.80 (at an $\alpha$ of $p=0.05$ ), $n=20$ animals in each group would be required. This analysis also demonstrated that the cytochrome $c$ control group was no different from normal

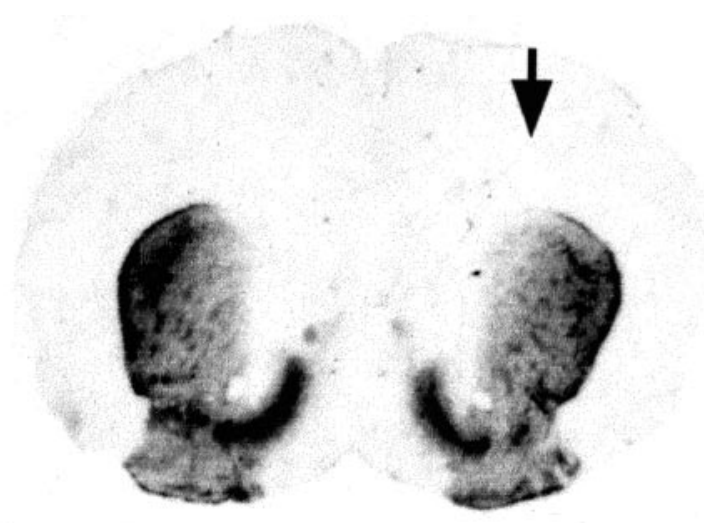

\section{A. CYTO C}

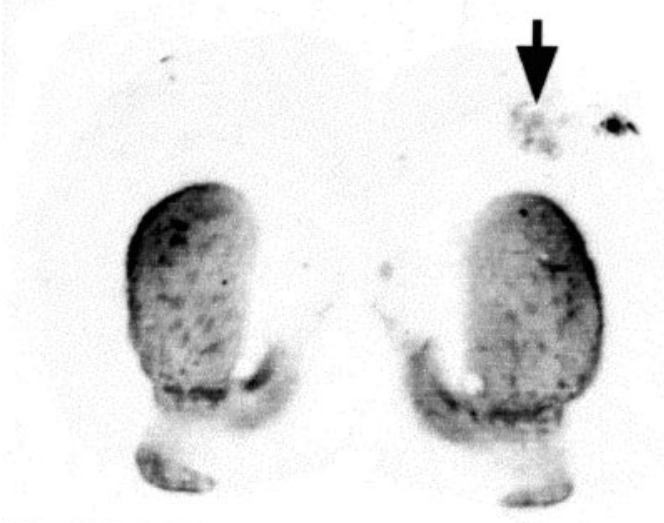

\section{B. BDNF}

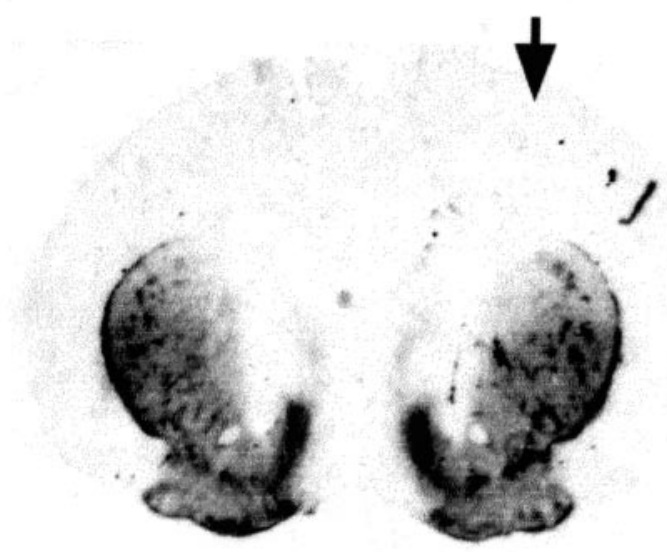

\section{GDNF}

Figure 4. Striatal TH immunoperoxidase staining after intrastriatal injections. These representative striatal coronal sections taken from animals injected with cytochrome $c(A ; C Y T O C)$, $\operatorname{BDNF}(B)$, or GDNF ( $C$ (the arrows indicate the injected slide) demonstrate that there is no increase in TH fiber staining in the striatum for any of the conditions, indicating that there has been no induction of sprouting. These striata were taken from animals used in the experiment presented in Figure 3. (noninjected) animals at this age, so the latter condition was excluded from additional analysis.

Intrastriatal injection of $1.0 \mu \mathrm{g} / 1.0 \mu \mathrm{l}$ GDNF (recombinant human GDNF; Amgen) in the larger cohort of animals demonstrated a $61 \%$ suppression of natural cell death among DA neurons of the $\mathrm{SN}$, assessed as total apoptotic profiles meeting regional or cellular criteria (Fig. 3A) compared with the cytochrome $c$ injection condition. When the analysis was restricted only to profiles meeting cellular criteria for apoptosis in TH-positive neurons, a significant effect was also observed (Fig. $3 B)$.

Suppression of natural cell death in SN DA neurons by GDNF is not attributable to local striatal effects

It is known from a variety of studies in adult animals of different species that GDNF can induce sprouting of the dopaminergic nigrostriatal system (Hudson et al., 1995; Tomac et al., 1995a; Rosenblad et al., 1998; Kordower et al., 2000). We therefore considered the possibility that, rather than acting directly to suppress
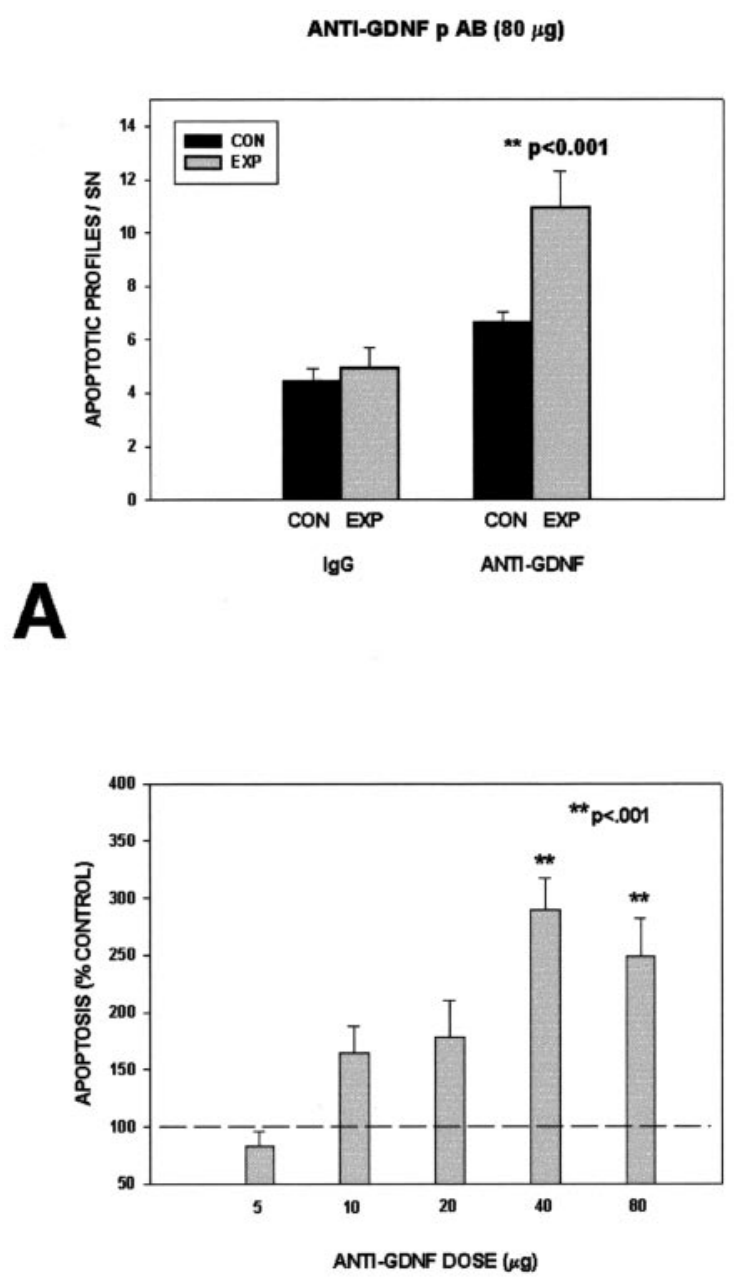

B

Figure 5. Intrastriatal injection of a polyclonal anti-GDNF neutralizing antibody induces developmental cell death in DA neurons of the SN. A, At a maximal dose of $80 \mu \mathrm{g}$, anti-GDNF ( $n=6$ ) induces cell death $\sim 2.5$-fold at $24 \mathrm{hr}$ after injection. At this dose, control affinitypurified goat lgG $(n=6)$ is without effect. $B, A$ dose-response analysis demonstrates that a maximal effect is achieved at $40 \mu \mathrm{g}(n=6)$; doses of $10(n=7)$ and $20(n=5) \mu \mathrm{g}$ have intermediate effects. No effect was observed at a dose of $5 \mu \mathrm{g}(n=6)$. 


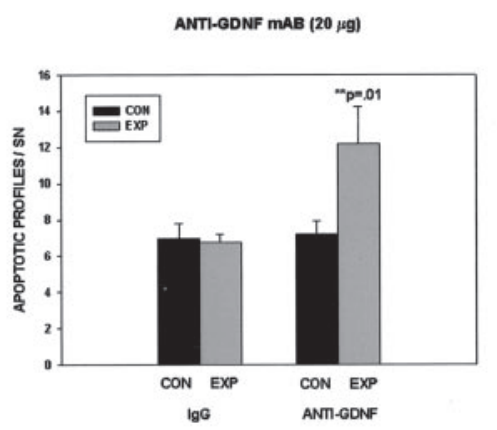

A
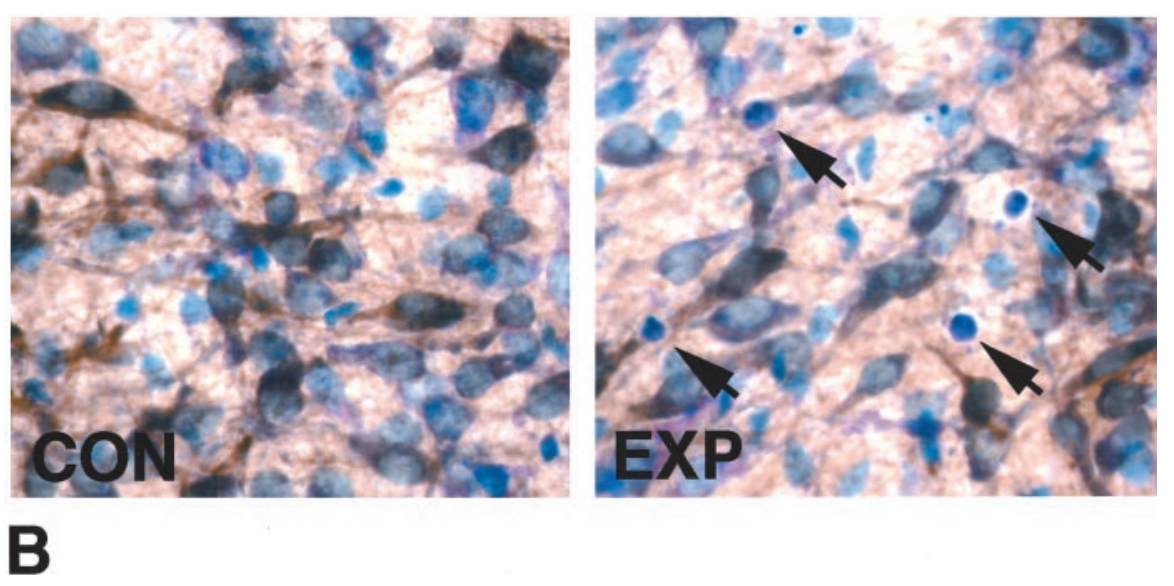

Figure 6. Intrastriatal injection of a mouse monoclonal anti-GDNF antibody induces developmental cell death in DA neurons of the SN. $A, A 20 \mu$ injection of antibody induces cell death approximately twofold at $24 \mathrm{hr}$ after injection (anti-GDNF antibody, $n=$ 7; IgG control, $n=6$ ). B, The control (CON) and experimental (EXP) sides of the SNpc of an animal injected with monoclonal antibody (MAB212; R\&D Systems) are shown in a section that has been TH immunoperoxidase stained to demonstrate DA neurons and thionin counterstained to demonstrate apoptotic profiles (arrows). There is an induction of apoptosis on the injected side.

cell death in DA neurons via terminal binding and retrograde transport, GDNF may instead be acting by an induction of sprouting within DA axons, allowing their terminals to take up more of some other trophic molecule. To assess this possibility, we performed immunoperoxidase staining for tyrosine hydroxylase-positive fibers within the striatum after GDNF and control injections. These studies showed that, within the timeframe of our analysis ( $1 \mathrm{~d}$ after injection), there was no apparent induction of sprouting. A quantitative analysis of striatal optical densities was performed on two sections within Paxinos-Watson planes 9.2 or 9.7 for each of five animals in each of the three conditions. This analysis revealed that there was no difference among the groups or compared with the contralateral, noninjected control sides: cytochrome $c$ control (C), $0.032 \pm 0.004$ optical density units; cytochrome $c$ experimental (E), $0.030 \pm$ 0.004; BDNF C, $0.033 \pm 0.003$; BDNF E, $0.031 \pm 0.003$; GDNF C, $0.032 \pm 0.003$; GDNF E, $0.035 \pm 0.002$. Representative sections are shown in Figure 4.

We also considered the possibility that, rather than acting directly on the dopaminergic neurons, GDNF may act to suppress natural cell death within the striatal target neurons. Such an effect would permit augmentation of target, which may, in turn, suppress natural cell death within DA neurons. An analysis of the number of apoptotic profiles within the striatum after GDNF injection showed no effect (injected, $2.5 \pm 0.6$ apoptotic profiles; noninjected, $1.9 \pm 0.5 ; n=5$ ). There was a trend for BDNF to suppress natural cell death in striatum (injected, $1.1 \pm 0.1$; noninjected, $1.9 \pm$ $0.5)$, but this effect did not reach significance ( $p=0.08$; ANOVA). In addition, there was no effect of any of the injections on the mean cross-sectional area of the striatum.

\section{Developmental cell death in SN DA neurons is augmented by intrastriatal injection of anti-GDNF neutralizing antibodies}

To determine whether endogenous striatal GDNF may play a role in regulating the magnitude of the natural cell death event in SN DA neurons, we performed passive immunization studies by injection of antiGDNF antibodies with proven in vitro neutralizing ability. Assessed $24 \mathrm{hr}$ after intrastriatal injection, $\mathrm{AB}-212-\mathrm{NA}$ ( R \& D Systems) induced a twofold to threefold increase in the levels of apoptotic profiles in $\mathrm{SN}$, identified by combined regional and cellular criteria (Fig. 5). Dose-response analysis indicated that a maximal effect was achieved at $40 \mu \mathrm{g}$ of anti-GDNF IgG; doses of 10 and $20 \mu \mathrm{g}$ had intermediate effects. Examination of the striatal injection site revealed minimal and similar traumatic injury along the cannula tract in both the anti-GDNF and the goat IgG control conditions.

To confirm this effect, additional experiments were performed with MAB212 (R \& D Systems), a mouse monoclonal with proven ability to neutralize GDNF (Arce et al., 1998). Like AB-212-NA (R \& D Systems), MAB212 induced an approximate twofold increase in apoptosis at a dose of $20 \mu \mathrm{g}$ (Fig. 6).

We showed previously that developing SN DA neurons undergo induction of apoptotic cell death if the striatal target is lesioned up to P14 but not thereafter (Macaya et al., 1994; Kelly and Burke, 1996). To determine whether there is a similar developmental time period during which these neurons are sensitive to induction of death by intrastriatal injection of anti-GDNF antibody, we examined the effect of a maximal dose $(40 \mu \mathrm{g})$ of AB212-NA at different times during development. This analysis showed that the antibody was able to induce death at P2 and P7 but not at P14 or P21 (Fig. 7).

\section{Discussion}

In support of the hypothesis that GDNF is a limiting, striatal target-derived neurotrophic factor for developing SN DA neurons, we demonstrated that intrastriatal injection results in a reduction of natural cell death during the first major phase just after birth. We showed that this effect is not attributable to two possible local striatal effects, either an induction of sprouting in dopaminergic fibers or a suppression of apoptosis in the striatal target. On the basis of our previous quantitative analyses of the natural cell death event in these neurons (Janec and Burke, 1993; Oo and Burke, 1997), indicating that the prevalence of apoptotic profiles is low even at the peaks of cell death, we anticipated that a considerable number of animals would be required to demonstrate 


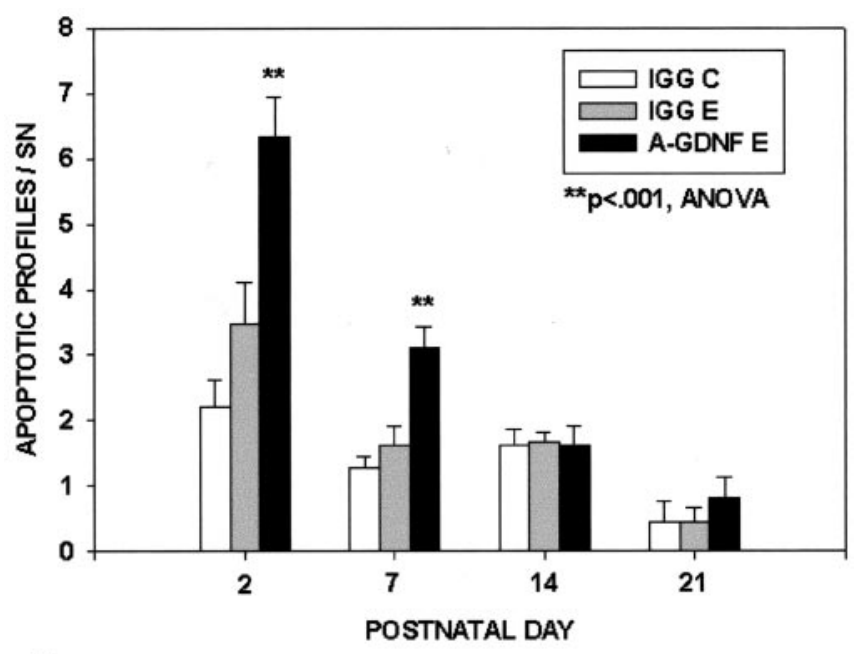

A

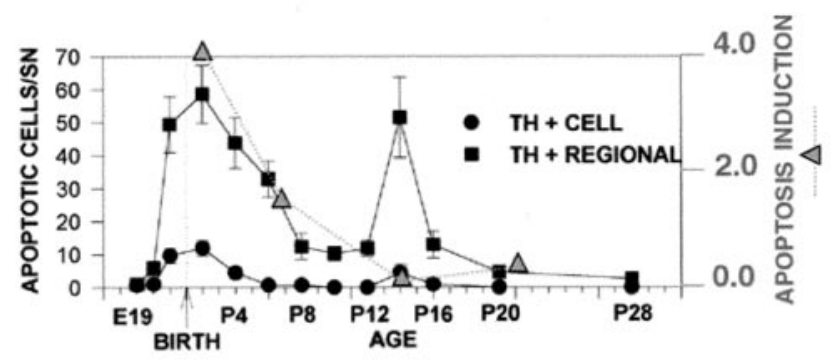

B

Figure 7. The ability of anti-GDNF neutralizing antibodies to induce apoptosis in SN DA neurons is developmentally dependent. $A$, Forty micrograms of anti-GDNF polyclonal antibody were injected into the striatum of rats at the indicated ages, and they were killed the next day. A significant induction of cell death was observed at P2 and P7 but not at P14 or P21. $n=12$ animals were studied at each age; $n=6$ received anti-GDNF; $n=6$ received lgG control injection. $B$, The magnitude of apoptosis induction, expressed as the difference between the number of profiles on the anti-GDNF experimental (E) and the IgG noninjected control (C) conditions, is plotted as a function of developmental age in relation to the known time course of natural cell death in DA neurons ( 00 and Burke, 1997). It can be seen that the maximal effect of anti-GDNF occurs during the first phase of natural cell death at P2; during the second phase at P14, there is no effect. E19, Embryonic day 19.

an effect, and this was borne out by a power analysis of pilot data. The large number of animals required at this single dose precluded a detailed dose-response study, so we do not know the minimal dose sufficient to demonstrate this effect. At the dose used, it is not possible to be certain that effects of the injection are restricted to striatal GFR $\alpha 1$ receptors, which are believed to be primarily responsible for mediating physiologic GDNF effects in vivo (Rosenthal, 1999). Given evidence that GDNF has an ability, albeit limited, to compete with neurturin at GFR $\alpha 2$ binding sites (Leitner et al., 1999), it is possible that the effect we observed may be mediated, at least in part, by a neurturin-like effect. Like GDNF, neurturin mRNA is also expressed in the postnatal rat striatum (Akerud et al., 1999), so it may also play a role in regulation of natural cell death in DA neurons. We hypothesize that, after intrastriatal injection, GDNF acts at dopaminergic terminals and, after retrograde transport, acts at the neuron cell body to inhibit apoptosis, as envisioned by classic neurotrophic theory (Barde, 1989).

To further explore a specific, direct role for GDNF and to determine whether endogenous GDNF plays a role, we used a passive immunization approach with neutralizing antibodies. There are well established precedents for the use of this approach to examine the physiologic roles of neurotrophic factors in the CNS (Vantini et al., 1989; Giehl et al., 1998). Our experiments demonstrated that local neutralization of GDNF within the striatum results in an induction of cell death within DA neurons of the SN. A dose-response analysis indicated that intermediate effects were observed with the polyclonal antibody at 10 and $20 \mu \mathrm{g}$, whereas maximal effects were observed at $40 \mu \mathrm{g}$. A similar, approximately twofold level of induction was observed with the monoclonal antibody at $20 \mu \mathrm{g}$. It is difficult to meaningfully compare these doses with those used by others in similar experiments because the relative affinities of the antibodies used are unknown. Nevertheless, considered on a molar basis, our lowest effective dose of the polyclonal, $10 \mu \mathrm{g}$, is comparable with doses used by Vantini et al. (1989) of Fab fragments. In addition, it would be expected that IgG molecules, as we used, would have much more limited diffusion capacity than Fab fragments, necessitating a higher dose to achieve a biologic effect. The ability of two different, specific neutralizing antibodies to GDNF to induce natural cell death strongly suggests that endogenous GDNF, and not some other GDNF family ligand, is regulating this cell death event at the striatal level. Neither antibody cross-reacted with other GDNF family ligands.

We showed previously that the first 2 postnatal weeks are a critical period in the development of SN DA neurons. It is during this period that their natural cell death event occurs (Janec and Burke, 1993; Oo and Burke, 1997; Jackson-Lewis et al., 2000) and that they appear to be most dependent on target interactions. During the first 2 weeks, but not afterward, an axon-sparing excitotoxic lesion of the target striatum induces the death event (Macaya et al., 1994; Kelly and Burke, 1996). We therefore sought to determine whether there would be a similar developmental time course of sensitivity to blockade of GDNF signaling by passive immunization. These studies did reveal a critical developmental window for this effect, but it was of shorter duration, lasting only through P7. This result suggests that, if there continues to be a striatal target dependence between P7 and P14, it may be on the basis of support by some other neurotrophic factor besides GDNF. It is unlikely that the decreasing ability of the anti-GDNF antibody to induce death is simply attributable to growth of the striatum and a diminished ability to diffuse fully into it. Fentress et al. (1981) have shown that, between P4 and P8, the volume of the developing rat striatum increases only $\sim 1.7$ fold, whereas our data would predict a threefold to fourfold decrease in the induction of cell death. In accord with our interpretation that another target factor becomes critical during the second postnatal week, there are precedents for a change in supporting neurotrophic factors during development. For example, patterns of neurotrophin expression evolve during development to suggest a later role for BDNF (Maisonpierre et al., 1990).

Our studies show that GDNF now fulfills additional criteria for a target-derived, limiting, neurotrophic factor for developing SN DA neurons. It has been shown previously that its mRNA is present, and most abundant, in the developing striatum (Schaar et al., 1993; Stromberg et al., 1993; Blum and Weickert, 1995; Choi-Lundberg and Bohn, 1995; Golden et al., 1999). GDNF protein expression in striatum is also most abundant shortly after birth (Lopez-Martin et al., 1999). The GDNF receptor GFR $\alpha 1$ 
and the transmembrane tyrosine kinase Ret are both expressed in SNpc (Treanor et al., 1996; Glazner et al., 1998; Yu et al., 1998). GDNF can be specifically transported retrograde from striatum to $\mathrm{SNpc}$ (Tomac et al., 1995b). In vitro, in a postnatal culture model established at the peak of natural cell death in DA neurons, GDNF is able to support viability by suppression of apoptosis (Burke et al., 1998). We now show that GDNF meets two additional criteria in vivo. When injected into the striatum during the first phase of the natural cell death event, it suppresses apoptosis, and, when its biologic activity in the striatum is blocked by neutralizing antibodies, it induces apoptosis. We therefore conclude that the available evidence supports GDNF as the leading candidate for a target-derived neurotrophic factor for SN DA neurons. This conclusion is supported by studies by Granholm et al. (2000) using transplantation of GDNF null mouse mesencephalon into the brain of adult wild-type mice, which demonstrated a dependence of DA neurons on GDNF for their survival.

What additional criteria need to be fulfilled to convincingly demonstrate that GDNF is a physiologic, target-derived neurotrophic factor for SN DA neurons? First, if it is such a factor, then its overexpression in the striatal target throughout the period of natural cell death should result in an augmented number of SN DA neurons surviving into maturity. It is important to note that, although single intrastriatal injections of GDNF had no effect on the mature number of DA neurons (Beck et al., 1996), a single injection probably does not have an adequate duration of effect when one considers that the natural cell death period lasts 2 weeks. A transgenic approach, with regionally specific expression in SN DA neuron targets, will be required to address this question. Second, whereas our passive immunization data indicate that a molecule such as GDNF is likely to be playing a role, it is always possible, at the doses of antibody given, that there is crossreactivity and that some other related factor, but not GDNF, plays the essential role. To address this question definitively for GDNF, it will be essential to develop regionally selective and temporally regulated null mutations that are compatible with postnatal survival.

\section{References}

Akerud P, Alberch J, Eketjall S, Wagner J, Arenas E (1999) Differential effects of glial cell line-derived neurotrophic factor and neurturin on developing and adult substantia nigra dopaminergic neurons. J Neurochem 73:70-78.

Arce V, Pollock RA, Philippe JM, Pennica D, Henderson CE, deLapeyriere O (1998) Synergistic effects of schwann- and muscle-derived factors on motoneuron survival involve GDNF and cardiotrophin-1 (CT-1). J Neurosci 18:1440-1448.

Baloh RH, Tansey MG, Lampe PA, Fahrner TJ, Enomoto H, Simburger KS, Leitner ML, Araki T, Johnson Jr EM, Milbrandt J (1998) Artemin, a novel member of the GDNF ligand family, supports peripheral and central neurons and signals through the GFRalpha3-RET receptor complex. Neuron 21:1291-1302.

Barde YA (1989) Trophic factors and neuronal survival. Neuron 2:1525-1534.

Beck KD, Irwin I, Valverde J, Brennan T, Langston JW, Hefti F (1996) GDNF induces a dystonia-like state in neonatal rats and stimulates dopamine and serotonin synthesis. Neuron 16:665-673.

Blum M, Weickert CS (1995) GDNF mRNA expression in normal postnatal development, aging, and in weaver mutant mice. Neurobiol Aging 16:925-929.

Burke RE, Cadet JL, Kent JD, Karanas AL, Jackson-Lewis V (1990) An assessment of the validity of densitometric measures of striatal tyrosine hydroxylase-positive fibers: relationship to apomorphine-induced rotations in 6-hydroxydopamine lesioned rats. J Neurosci Methods 35:63-73.

Burke RE, Antonelli M, Sulzer D (1998) Glial cell line-derived neurotrophic growth factor inhibits apoptotic death of postnatal substantia nigra dopamine neurons in primary culture. J Neurochem 71:517-525.

Cacalano G, Farinas I, Wang LC, Hagler K, Forgie A, Moore M, Armanini M,
Phillips H, Ryan AM, Reichardt LF, Hynes M, Davies A, Rosenthal A (1998) GFRalphal is an essential receptor component for GDNF in the developing nervous system and kidney. Neuron 21:53-62.

Choi-Lundberg DL, Bohn MC (1995) Ontogeny and distribution of glial cell line-derived neurotrophic factor (GDNF) mRNA in rat. Brain Res Dev Brain Res 85:80-88.

Clarke PGH (1985) Neuronal death in the development of the vertebrate nervous system. Trends Neurosci 8:345-349.

Clarke PGH, Oppenheim RW (1995) Neuron death in vertebrate development: in vivo methods. In: Methods in cell biology: cell death (Schwartz LM, Osborne BA, eds), pp 277-321. New York: Academic.

Cowan WM, Fawcett JW, O'Leary DD, Stanfield BB (1984) Regressive events in neurogenesis. Science 225:1258-1265.

El-Khodor BF, Burke RE (2002) Medial forebrain bundle axotomy during development induces apoptosis in dopamine neurons of the substantia nigra and activation of caspases in their degenerating axons. J Comp Neurol 452:65-79.

El-Khodor BF, Oo TF, Kholodilov N, Burke RE (2003) Ectopic expression of cell cycle markers in models of induced programmed cell death in dopamine neurons of the rat substantia nigra pars compacta. Exp Neurol 179:17-27.

Enomoto H, Araki T, Jackman A, Heuckeroth RO, Snider WD, Johnson EMJ, Milbrandt J (1998) GFR alpha1-deficient mice have deficits in the enteric nervous system and kidneys. Neuron 21:317-324.

Fentress JC, Stanfield BB, Cowan WM (1981) Observations on the development of the striatum in mice and rats. Anat Embryol 163:275-298.

Freeman RS, Estus S, Johnson EM (1994) Analysis of cell cycle-related gene expression in postmitotic neurons selective induction of cyclin D1 during programmed cell death. Neuron 12:343-355.

Giehl KM, Schutte A, Mestres P, Yan Q (1998) The survival-promoting effect of glial cell line-derived neurotrophic factor on axotomized corticospinal neurons in vivo is mediated by an endogenous brain-derived neurotrophic factor mechanism. J Neurosci 18:7351-7360.

Glazner GW, Mu X, Springer JE (1998) Localization of glial cell line-derived neurotrophic factor receptor alpha and c-ret mRNA in rat central nervous system. J Comp Neurol 391:42-49.

Golden JP, DeMaro JA, Osborne PA, Milbrandt J, Johnson EM (1999) Expression of neurturin, GDNF, and GDNF family-receptor mRNA in the developing and mature mouse. Exp Neurol 158:504-528.

Granholm AC, Reyland M, Albeck D, Sanders L, Gerhardt G, Hoernig G, Shen L, Westphal H, Hoffer B (2000) Glial cell line-derived neurotrophic factor is essential for postnatal survival of midbrain dopamine neurons. J Neurosci 20:3182-3190.

Gundersen HJ (1986) Stereology of arbitrary particles: a review of unbiased number and size estimators and the presentation of some new ones, in memory of William R. Thompson. J Microsc 143:3-45.

Hemmendinger LM, Garber BB, Hoffmann PC, Heller A (1981) Target neuron-specific process formation by embryonic mesencephalic dopamine neurons in vitro. Proc Natl Acad Sci USA 78:1264-1268.

Hoffmann PC, Hemmendinger LM, Kotake C, Heller A (1983) Enhanced dopamine cell survival in reaggregates containing target cells. Brain Res 274:275-281.

Hudson J, Granholm AC, Gerhardt GA, Henry MA, Hoffman A, Biddle P, Leela NS, Mackerlova L, Lile JD, Collins F (1995) Glial cell line-derived neurotrophic factor augments midbrain dopaminergic circuits in vivo. Brain Res Bull 36:425-432.

Jackson-Lewis V, Vila M, Djaldetti R, Guegan C, Liberatore G, Liu J, O’Malley KL, Burke RE, Przedborski S (2000) Developmental cell death in dopaminergic neurons of the substantia nigra of mice. J Comp Neurol 424:476-488.

Janec E, Burke RE (1993) Naturally occurring cell death during postnatal development of the substantia nigra of the rat. Mol Cell Neurosci 4:30-35.

Kelly WJ, Burke RE (1996) Apoptotic neuron death in rat substantia nigra induced by striatal excitotoxic injury is developmentally dependent. Neurosci Lett 220:85-88.

Kordower JH, Emborg ME, Bloch J, Ma SY, Chu Y, Leventhal L, McBride J, Chen EY, Palfi S, Roitberg BZ, Brown WD, Holden JE, Pyzalski R, Taylor MD, Carvey P, Ling Z, Trono D, Hantraye P, Deglon N, Aebischer P (2000) Neurodegeneration prevented by lentiviral vector delivery of GDNF in primate models of Parkinson's disease. Science 290:767-773.

Kotzbauer PT, Lampe PA, Heuckeroth RO, Golden JP, Creedon DJ, Johnson 
Jr EM, Milbrandt J (1996) Neurturin, a relative of glial-cell-line-derived neurotrophic factor. Nature 384:467-470.

Leitner ML, Molliver DC, Osborne PA, Vejsada R, Golden JP, Lampe PA, Kato AC, Milbrandt J, Johnson Jr EM (1999) Analysis of the retrograde transport of glial cell line-derived neurotrophic factor (GDNF), neurturin, and persephin suggests that in vivo signaling for the GDNF family is GFR $\alpha$ coreceptor-specific. J Neurosci 19:9322-9331.

Lin LF, Doherty DH, Lile JD, Bektesh S, Collins F (1993) GDNF: A glial cell line-derived neurotrophic factor for midbrain dopaminergic neurons. Science 260:1130-1132.

Lopez-Martin E, Caruncho HJ, Rodriguez-Pallares J, Guerra MJ, LabandeiraGarcia JL (1999) Striatal dopaminergic afferents concentrate in GDNFpositive patches during development and in developing intrastriatal striatal grafts. J Comp Neurol 406:199-206.

Macaya A, Munell F, Gubits RM, Burke RE (1994) Apoptosis in substantia nigra following developmental striatal excitotoxic injury. Proc Natl Acad Sci USA 91:8117-8121

Maisonpierre PC, Belluscio L, Friedman B, Alderson RF, Wiegand SJ, Furth ME, Lindsay RM, Yancopoulos GD (1990) NT-3, BDNF, and NGF in the developing rat nervous system: parallel as well as reciprocal patterns of expression. Neuron 5:501-509.

Marti MJ, James CJ, Oo TF, Kelly WJ, Burke RE (1997) Early developmental destruction of terminals in the striatal target induces apoptosis in dopamine neurons of the substantia nigra. J Neurosci 17:2030-2039.

Milbrandt J, de Sauvage FJ, Fahrner TJ, Baloh RH, Leitner ML, Tansey MG, Lampe PA, Heuckeroth RO, Kotzbauer PT, Simburger KS, Golden JP, Davies JA, Vejsada R, Kato AC, Hynes M, Sherman D, Nishimura M, Wang LC, Vandlen R, Moffat B, et al. (1998) Persephin: a novel neurotrophic factor related to GDNF and neurturin. Neuron 20:245-253.

Moore MW, Klein RD, Farinas I, Sauer H, Armanini M, Phillips H, Reichardt LF, Ryan AM, Carver-Moore K, Rosenthal A (1996) Renal and neuronal abnormalities in mice lacking GDNF. Nature 382:76-79.

Oo TF, Burke RE (1997) The time course of developmental cell death in phenotypically defined dopaminergic neurons of the substantia nigra. Brain Res Dev Brain Res 98:191-196.

Oppenheim RW (1991) Cell death during development of the nervous system. Annu Rev Neurosci 14:453-501.

Parish CL, Finkelstein DI, Drago J, Borrelli E, Horne MK (2001) The role of dopamine receptors in regulating the size of axonal arbors. J Neurosci 21:5147-5157.

Paxinos G, Watson C (1982) The rat brain in stereotaxic coordinates. San Diego: Academic.

Pichel JG, Shen L, Sheng HZ, Granholm AC, Drago J, Grinberg A, Lee EJ,
Huang SP, Saarma M, Hoffer BJ, Sariola H, Westphal H (1996) Defects in enteric innervation and kidney development in mice lacking GDNF. Nature 382:73-76.

Prochiantz A, di Porzio U, Kato A, Berger B, Glowinski J (1979) In vitro maturation of mesencephalic dopaminergic neurons from mouse embryos is enhanced in presence of their striatal target cells. Proc Natl Acad Sci USA 76:5387-5391.

Rosenblad C, Martinez-Serrano A, Bjorklund A (1998) Intrastriatal glial cell line-derived neurotrophic factor promotes sprouting of spared nigrostriatal dopaminergic afferents and induces recovery of function in a rat model of Parkinson's disease. Neuroscience 82:129-137.

Rosenthal A (1999) The GDNF protein family: gene ablation studies reveal what they really do and how. Neuron 22:201-203.

Sanchez MP, Silos-Santiago I, Frisen J, He B, Lira SA, Barbacid M (1996) Renal agenesis and the absence of enteric neurons in mice lacking GDNF. Nature 382:70-73.

Schaar DG, Sieber BA, Dreyfus CF, Black IB (1993) Regional and cell specific expression of GDNF in rat brain. Exp Neurol 124:368-371.

Stromberg I, Bjorklund L, Johansson M, Tomac A, Collins F, Olson L, Hoffer B, Humpel C (1993) Glial cell line-derived neurotrophic factor is expressed in the developing but not adult striatum and stimulates developing dopamine neurons in vivo. Exp Neurol 124:401-412.

Tomac A, Lindqvist E, Lin LF, Ogren SO, Young D, Hoffer BJ, Olson L (1995a) Protection and repair of the nigrostriatal dopaminergic system by GDNF in vivo. Nature 373:335-339.

Tomac A, Widenfalk J, Lin LH, Kohno T, Ebendal T, Hoffer BJ, Olson L (1995b) Retrograde axonal transport of glial cell line-derived neurotrophic factor in the adult nigrostriatal system suggests a trophic role in the adult. Proc Natl Acad Sci USA 92:8274-8278.

Tomozawa Y, Appel SH (1986) Soluble striatal extracts enhance development of mesencephalic dopaminergic neurons in vitro. Brain Res 399:111-124.

Treanor JJ, Goodman L, de Sauvage F, Stone DM, Poulsen KT, Beck CD, Gray C, Armanini MP, Pollock RA, Hefti F, Phillips HS, Goddard A, Moore MW, Buj-Bello A, Davies AM, Asai N, Takahashi M, Vandlen R, Henderson CE, Rosenthal A (1996) Characterization of a multicomponent receptor for GDNF. Nature 382:80-83.

Vantini G, Schiavo N, Di Martino A, Polato P, Triban C, Callegaro L, Toffano G, Leon A (1989) Evidence for a physiological role of nerve growth factor in the central nervous system of neonatal rats. Neuron 3:267-273.

Yu T, Scully S, Yu Y, Fox GM, Jing S, Zhou R (1998) Expression of GDNF family receptor components during development: implications in the mechanisms of interaction. J Neurosci 18:4684-4696. 